\title{
Cluster analysis identifies a pathophysiologically distinct subpopulation with increased serum leptin levels and severe obstructive sleep apnea
}

\author{
Yutaka Kozu $^{1}$ (D) $\cdot$ Yusuke Kurosawa $^{1} \cdot$ Shiho Yamada $^{1} \cdot$ Asami Fukuda $^{1} \cdot$ Mari Hikichi $^{1} \cdot$ Hisato Hiranuma $^{1}$. \\ Toshiki Akahoshi ${ }^{1} \cdot$ Yasuhiro Gon ${ }^{1}$
}

Received: 20 March 2020 / Revised: 27 July 2020 / Accepted: 1 August 2020 / Published online: 4 September 2020

(C) The Author(s) 2020

\begin{abstract}
Purpose To investigate the different pathophysiologies of obstructive sleep apnea (OSA) phenotypes using cluster analysis. Differences between leptin/adiponectin levels in the resulting OSA phenotypes were also examined.

Methods In total, 1057 OSA patients were selected, and a retrospective survey of clinical records, polysomnography results, and blood gas data was conducted. Patients were grouped into four clusters by their OSA severity, PaCO2, body mass index (BMI), and sleepiness. A $k$-means cluster analysis was performed, resulting in a division into four subpopulations. The Tukey or GamesHowell tests were used for intergroup comparisons.

Results Among the 20 clinical OSA items, four common factors (Epworth Sleepiness Scale [ESS], BMI, Apnea-Hypopnea Index $[\mathrm{AHI}]$, and $\mathrm{PaCO} 2$ ) were extracted by principal component analysis, and a cluster analysis was performed using the $k$-means method, resulting in four distinct phenotypes. The Clusters 1 (middle age, symptomatic severe OSA) and 4 (young, obese, symptomatic very severe OSA) exhibited high leptin levels. C-reactive protein levels were also elevated in Cluster 4, indicating a different pathophysiological background. No apparent differences between clusters were observed regarding adiponectin/leptin ratios and adiponectin levels. Classification into groups based on phenotype showed that Epworth Sleepiness Scale [ESS] score and disease severity were not correlated, suggesting that sleepiness is affected by multiple elements.

Conclusions The existence of multiple clinical phenotypes suggests that different pathophysiological backgrounds exist such as systemic inflammation and metabolic disorder. This classification may be used to determine the efficacy of continuous positive airway pressure treatment that cannot be determined by the AHI.
\end{abstract}

Keywords Obstructive sleep apnea $\cdot$ Phenotypes $\cdot$ Cluster analysis $\cdot$ Leptin $\cdot$ Blood gas analysis

\section{Introduction}

The prevalence of obstructive sleep apnea (OSA) was reported 20 years ago by Young and colleagues, affecting up to $9 \%$ of men and $4 \%$ of women [1-4]. Although there have been no major epidemiological studies in Japan, OSA prevalence rates in men in their $40 \mathrm{~s}$ and $50 \mathrm{~s}$ are $23.4 \%$ and $30.6 \%$, respectively

Yutaka Kozu

kozu.yutaka@nihon-u.ac.jp

1 Division of Respiratory Disease, Nihon University School of Medicine, 30-1 Ohyaguchi-Kamicho, Itabashiku, Tokyo 173-8610, Japan
[2]. The OSA prevalence in Japan is comparable with that in Europe and the USA.

OSA substantially complicates cardiovascular diseases and they are important factors in determining the OSA prognosis. Repeated nocturnal hypoxemia is an important factor, and hypertension or diabetes mellitus is frequently involved. Thus, OSA is considered to overlap with various risk factors related to cardiovascular system disorders [3]. It is also recognized as being composed of multiple phenotypes; its diagnosis and management as well as the assessment of its severity are often based on a single indicator, the Apnea-Hypopnea Index (AHI) [5]. Taking the diverse OSA pathologies into consideration is important for a more fine-tuned OSA management.

Cytokines secreted from adipose tissue play an important role in the pathophysiology of obesity; the relationship between obesity and sleep-disordered breathing is well-known. 
Among adipokines, leptin and adiponectin have attracted the most attention [6]. Despite the anti-obesity effects of leptin, obese individuals have elevated serum leptin levels, and administering leptin to obese individuals only produces an extremely limited impact on obesity. Since this is the result of reduced sensitivity to leptin signaling, leptin resistance is involved in obesity [7]. Leptin does not only act in the appetite center but is also involved in the ventilatory response [8].

There have been recent efforts to stratify patients by using clinical findings as indicators to understand the disease mechanism, predict risk, estimate prognosis, and select optimal treatment [9]. Patient populations classified in this manner are called "phenotypes" and may not only reflect classification by clinical features but also pathophysiological characteristics.

Taking the different phenotypes of OSA into consideration has the potential to better understand the underlying pathophysiology and to properly manage treatment according to trends in arousal, ventilatory sensitivity, and other pathophysiological features [10]. The main advantages of numerical classification are its objectivity and the fact that a methodology for including multiple variables, assuming equal weighting, helps minimize a priori bias and extract clusters that are important for exploratory purposes.

To classify the clinical OSA phenotypes, we hypothesized that it would be possible to identify the most important factors from variables made up of multiple clinical indicators and that the subsequent cluster analysis would enable us to identify phenotypes reflective of different OSA pathophysiologies. To test this hypothesis, a $k$-means clustering algorithm was used in the present study to investigate mild-to-severe OSA diagnosed based on polysomnography (PSG) testing at our center.

Therefore, this study aimed to investigate the different pathophysiological OSA phenotypes by clustering patients with OSA according to different clinical indicators and examine the cluster differences in leptin and adiponectin levels.

\section{Materials and methods}

Our study was approved by the Clinical Research Ethics Committee of the Nihon University Hospital (Protocol number RK-170509-07). Written informed consent was waived by the ethics committee. All protocols and practices were conducted following the World Medical Association's Declaration of Helsinki.

\section{Subjects}

Medical records of 3214 patients with obstructive sleep apnea among patients, who visited the Nihon University Sleep Center between April 1, 2002, and March 31, 2017, with suspected sleep apnea syndrome and were diagnosed based on the PSG results, were registered in a database. Overnight PSG was performed in 2191 patients with suspected OSA who visited Nihon University Itabashi Hospital Sleep Center; of these, 2174 were diagnosed with OSA. Of these, 1057 individuals whose clinical records, PSG data, and blood gas data were available, were finally enrolled in the present study. The following patients were excluded: OSA patients who did not agree to participate in the study, those who were aged $<20$ years, and those who had not undergone PSG and respiratory function tests.

\section{Polysomnography}

PSG was conducted by trained professional inspectors in all cases. The following items were recorded: electroencephalogram, electrooculogram, electrocardiogram, electromyogram, nose and mouth airflow, chest and abdomen movement, and peripheral capillary oxygen saturation (SpO2). Apnea was defined as airflow cessation in the nose and mouth lasting at for least $10 \mathrm{~s}$. Hypopnea was defined as decreased airflow, thoracic excursion, or decreased oxygen desaturation below $4 \%$ of the previous baseline value and decreased abdominal excursion below 50\%. The AHI was calculated as the apnea and hypopnea counts per hour of sleep. The diagnostic criteria for OSA were AHI $\geq 5$ times $/ \mathrm{h}$. The severity was defined as mild for AHI 5-15 times/h, moderate for 15-30 times/h, and severe for $\geq 30$ times $/ \mathrm{h}$. The CPAP adaptation standard in Japan is AHI $\geq 20$ times $/ \mathrm{h}$, and most cases in this study had an AHI of 20 times/h or more.

Average and minimum $\mathrm{SpO} 2$ values were also calculated from the PSG data. Baseline clinical features were assessed, and blood tests were also performed.

\section{Blood tests}

For blood counts and general biochemical testing, data were obtained from general medical records. Serum leptin and adiponectin levels were measured in all patients when residual samples were available after the blood test. Leptin and adiponectin were measured using the Human Leptin Assay Kit (catalog number \#27775; IBL, Inc., Gunma, Japan) and Human Adiponectin ELISA Kit (catalog number \#CY-8050; CircuLex, Inc., Nagano, Japan), respectively.

\section{Spirometry}

Conventional spirometry was performed using a Chestak auto-spirometer (Chest Co., Tokyo, Japan). Spirometric predictions were obtained from the literature [11], and samples for the arterial blood gas analysis were taken from the radial artery in a sitting position. 
The criterion for obstructive ventilatory dysfunction was defined as $70 \%$ or less per second, and the criterion for restrictive ventilatory dysfunction was $80 \%$ or less vital capacity.

\section{Blood gas analysis}

Arterial blood samples were analyzed using an ABL3000 auto-analyzer (Radiometer Co., Tokyo, Japan).

\section{ESS score}

Daytime sleepiness was assessed using the Epworth Sleepiness Scale (ESS) [12], a fully validated eight-item self-administered questionnaire. Eight different situations were scored on a scale of $0-3$, with more than 10 out of 24 scores rated as sleepiness.

\section{Statistical methods}

The $k$-means method was considered to be suitable considering that a relatively large number of samples were classified into four clusters in this study. The principal component analysis was used as a simple method for confirming the clustering of data (Fig. 1). The required number of subjects was determined from the independent variables while performing a multi-group comparison of each cluster, and the sample size was sufficient ( $n>64$ ) even when the power was set to $80 \%$. Results are presented as mean \pm standard deviation (SD). AHI, partial pressure of carbon dioxide $(\mathrm{PaCO} 2)$, body mass index (BMI), and ESS were obtained as four higher level components from eigenvalues, contribution rates, and cumulation.

The $k$-means cluster analysis was performed based on these four principal components, resulting in four subpopulations (Fig 2 ). The resulting data were tested for equality of variance between the clusters in each of the items. For equal variance, the one-way ANOVA with Tukey's all column comparison test was used for intergroup comparisons. Otherwise, intergroup comparisons were performed using the nonparametric Games-Howell test. If an $F$-value was $>4, p$ values $<0.05$ were considered statistically significant. (Text Explorer module of JMP Pro 13)

\section{Results}

\section{Patient characteristics}

Of the 1057 registered patients, 24 (3.2\%) had incomplete or absent data, or chiefly presented central sleep apnea or hypopnea. These patients were excluded from the analysis. The remaining 1023 patients diagnosed with OSA had a mean age of 51.4 years, ranging from 20 to 83 years, with $88 \%$ being men. The percentage of current smokers was around $24 \%$. The mean neck circumference was about $40 \mathrm{~cm}$, which was higher than an average Japanese adult. The self-reported day time sleepiness was assessed using the ESS and the mean score was 9.7 points (Table 1).

The cluster analysis identified four clusters. Compared with the Clusters 1 and 2, Cluster 3 was older and the Cluster 4 younger. There were no significant differences in male-female ratio or history of smoking between the clusters. The BMI values, as well as the neck, waist, and hip circumferences, were highest in Cluster 4. ESS scores were elevated in Clusters 1 and 4 (Table 2).

Table 3 shows the PSG results. Of the enrolled OSA patients, 95 (9\%) had mild (AHI 5-15/h), 200 (20\%) had moderate (AHI 15-30/h), and $728(71 \%)$ had severe $($ AHI $>30 / \mathrm{h})$ OSA, with a mean AHI of $47(/ \mathrm{h})$ and a mean oxygen desaturation index of $50 / \mathrm{h}$. Sleep-disordered breathing data (obstructive apnea (OA), apnea index (AI), AHI, oxygen desaturation index 3\%, mean $\mathrm{SpO} 2$, and arousal index) was the worst in Cluster 4, followed by Cluster 2 .

Table 4 displays the results of the lung function test. Although no ventilatory dysfunction was observed, the forced vital capacity $(\mathrm{FVC})$ and the forced expiratory volume $\left(\mathrm{FEV}_{1.0}\right)$ were the lowest in Cluster 4. There were no significant differences regarding the peripheral airway obstruction. The results of the arterial blood gas tests are shown in Table 4. Overall, CO2 tended to be high with metabolic compensation. Especially in Cluster 4, the mean value above $45 \mathrm{mmHg}$ was substantially increased. Besides, oxygen at rest tended to be low in this cluster.

According to the blood test data (Table 5), the white and red blood cell count, as well as the hemoglobin levels, were increased in Clusters 2 and 4. Similarly, liver function parameters, uric acid levels, and the values of a high-sensitivity test that detects $\mathrm{C}$ reactive protein (CRP) were increased, particularly in Cluster 4.

\section{Cluster analysis}

\section{Cluster 1 (290 subjects, 28.3\%); middle age, symptomatic severe OSA}

This cluster was centered on the middle-aged participants with a mean age of $51.00 \pm 12.71$ years. The mean BMI of patients belonging to this cluster was $26.20 \pm 3.45\left(\mathrm{~kg} / \mathrm{m}^{2}\right)$. Based on the BMI $\left(\mathrm{kg} / \mathrm{m}^{2}\right)$ classification (normal weight, 18.5-24.9; overweight, 25.0-29.9; and obese $>30$ ), these patients were mildly overweight. The mean ESS score of this cluster was $14.40 \pm 3.15$, indicating the most symptomatic excessive daytime sleepiness (EDS) of all clusters. The AHI, however, was with $36.17 \pm 18.66(/ \mathrm{h})$, far below the overall average.

\section{Cluster 2 (271 subjects, 26.5\%); middle age, obese, minimally symptomatic, very severe OSA}

Like Cluster 1, this cluster was centered on the middle-aged participants with a mean age of $49.10 \pm 12.71$ years. Their 
Fig. 1 Principal component analysis a

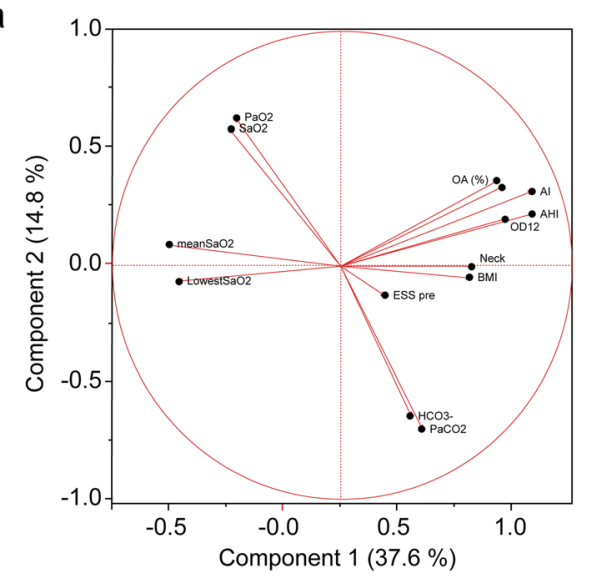

b

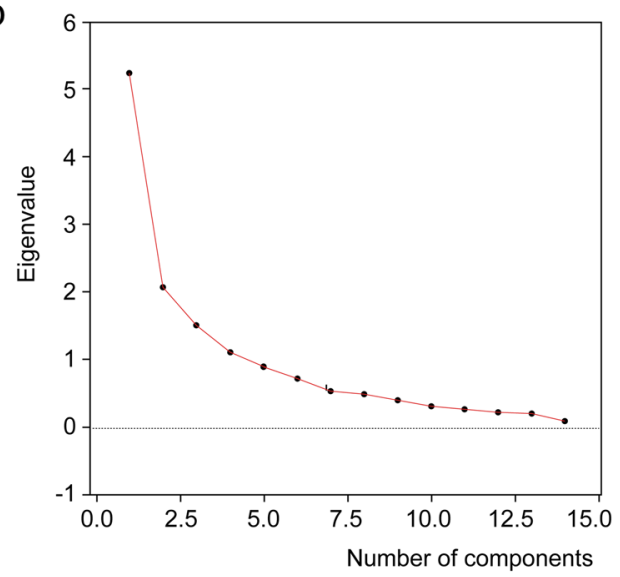

C

\begin{tabular}{rllll}
$\#$ & Eigenvalue & $\begin{array}{l}\text { Contribution } \\
\text { rate }\end{array}$ & $\begin{array}{l}\text { Cumulative } \\
\text { contribution } \\
\text { rate }\end{array}$ \\
\hline 1 & 5.2621 & 37.586 & +++ & 37.586 \\
2 & 2.0701 & 14.786 & + & 52.373 \\
3 & 1.5038 & 10.742 & + & 63.114 \\
4 & 1.1024 & 7.875 & & 70.989 \\
5 & 0.8879 & 6.342 & 77.331 \\
6 & 0.7073 & 5.052 & 82.383 \\
7 & 0.5273 & 3.767 & 86.149 \\
8 & 0.4754 & 3.396 & 89.545 \\
9 & 0.396 & 2.829 & 92.374 \\
10 & 0.3072 & 2.194 & 94.568 \\
11 & 0.2661 & 1.901 & 96.469 \\
12 & 0.2193 & 1.566 & 98.035 \\
13 & 0.1884 & 1.346 & 99.381 \\
14 & 0.0867 & 0.619 & 100 \\
\hline
\end{tabular}

mean BMI was $30.30 \pm 3.74\left(\mathrm{~kg} / \mathrm{m}^{2}\right)$, with many patients found to be obese. The mean ESS score of this cluster was $8.40 \pm 3.45$, making this cluster a population with a low ESS score and a decreased likelihood to present with EDS symptoms among all clusters (Table 2). Yet, the AHI was $56.00 \pm$ 20.02(/h), representing severe apnea and hypopnea.

\section{Cluster 3 (361 subjects, 35.3\%); oldest age, obese, minimally symptomatic, severe OSA}

This cluster was centered on middle-aged patients with a mean age of $55.24 \pm 13.29$ years. The mean BMI of patients belonging to this cluster was $25.15 \pm 3.48\left(\mathrm{~kg} / \mathrm{m}^{2}\right)$, indicating that they were mildly overweight. The mean ESS score of this cluster was $5.63 \pm 2.60$, suggesting the most limited EDS symptoms of all clusters (Table 2). The AHI was $31.34 \pm$ $15.53(/ \mathrm{h})$, which was far below the overall mean for AHI.
This cluster was accordingly composed of non-obese OSA patients, equivalent to mild-to-moderate symptoms (Table 3).

\section{Cluster 4 (101 subjects, 9.9\%); young age, obese, symptomatic very severe OSA}

This cluster was composed of relatively young patients with a mean age of $42.71 \pm 10.96$ years. The mean BMI of these patients was $36.87 \pm 6.04\left(\mathrm{~kg} / \mathrm{m}^{2}\right)$, indicating severe obesity. The mean ESS score of this cluster was $13.70 \pm 4.03$, suggesting the strongest EDS symptoms of all clusters (Table 2). Accordingly, with an AHI of $68.20 \pm 18.66(/ \mathrm{h})$, this cluster presented the most severe OSA of all clusters (Table 3 ). Respiratory function testing with a $\mathrm{FEV}_{1.0} \%$ of $77.61 \%$ did not detect airflow obstructions, but the $\mathrm{FEV}_{1.0}$ of $86.55 \%$ was significantly lower than that in other clusters (Table 4). As shown by the blood gas analysis, $\mathrm{PaO}_{2}$ at $72.57 \pm 9.00$ Torr 
Fig. 2 Cluster analysis ( $k$-means)

a

\begin{tabular}{cc}
\hline Cluster & $\#$ \\
\hline 1 & 290 \\
2 & 271 \\
3 & 361 \\
4 & 101 \\
\hline
\end{tabular}

b

Cluster average

\begin{tabular}{clccc}
\hline Cluster & AHI & PaCO2 & BMI & ESS \\
\hline 1 & 36.17 & 43.95 & 26.2 & 14.4 \\
2 & 69.63 & 42.96 & 30.3 & 8.402 \\
3 & 31.74 & 42.12 & 25.15 & 5.633 \\
4 & 76.3 & 47.88 & 36.87 & 13.7 \\
\hline
\end{tabular}

C

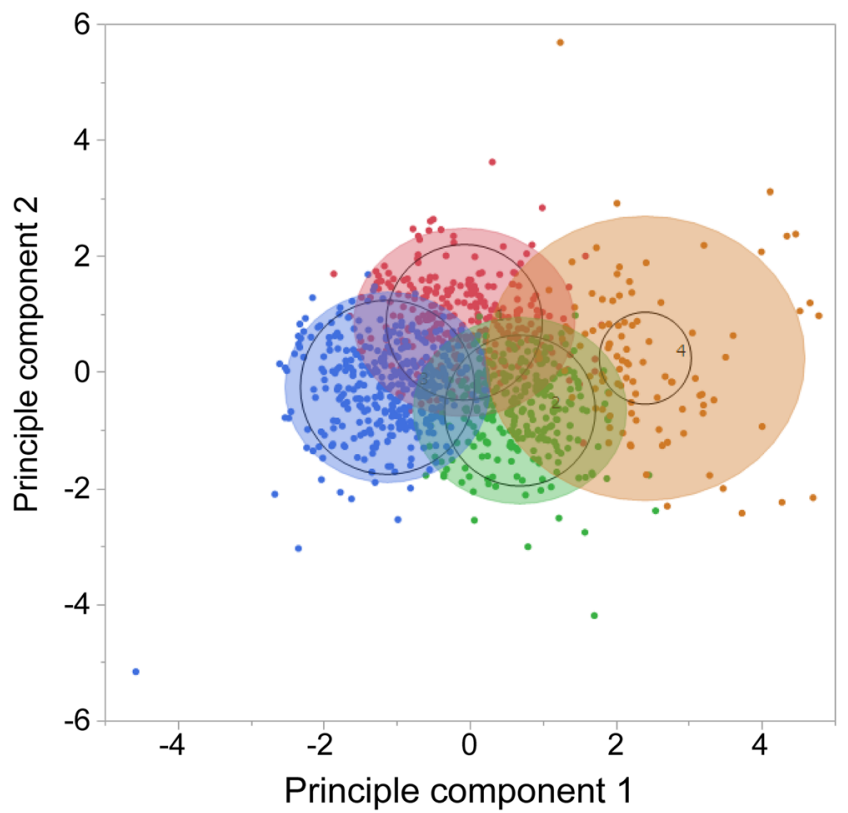

was the lowest despite this group being the youngest of all cluster populations. The $\mathrm{PaCO} 2$ was $47.88 \pm 5.43$ Torr indicating hypercapnia (Table 5). Blood tests also showed higher levels than other clusters with the white blood count at $8.44 \pm$ $2.08 / \mu \mathrm{L}$ and h-CRP at $4.8 \pm 12 \mu \mathrm{g} / \mathrm{mL}$. GOT and GPT

Table 1 Patient characteristics

\begin{tabular}{lll}
\hline & & $\begin{array}{l}\text { All clusters } \\
N=1023\end{array}$ \\
\hline Age & Year & 51.41 \\
Female & Number & 121 \\
Sex (female) & $\%$ & 11.8 \\
Smoker & $(n)$ & 249 \\
Ex-smoker & $(n)$ & 262 \\
Body mass index & $\left(\mathrm{kg} / \mathrm{m}^{2}\right)$ & 27.97 \\
Neck & $(\mathrm{cm})$ & 40.27 \\
Waist & $(\mathrm{cm})$ & 95.50 \\
Hip & $(\mathrm{cm})$ & 104.17 \\
ESS score & & 9.65 \\
\hline
\end{tabular}

ESS Epworth Sleepiness Scale indicated hepatic dysfunction with $39.10 \pm 23.37$ and 62.34 $\pm 43.37 \mathrm{U} / \mathrm{L}$, respectively. T-Cho, LDL, HbA1c, and UA also exhibited the highest values out of all clusters (Table 6).

\section{Comparison of serum leptin and adiponectin levels}

Serum leptin and adiponectin levels were determined in 167 patients whose samples were still available and compared between the four clusters (Table 6). Of the identified clusters, Clusters 1 and 4 exhibited high leptin levels. Adiponectin/ leptin ratios and adiponectin levels showed no clear differences between the clusters.

\section{Discussion}

\section{Summary of result}

Four common factors (ESS, BMI, AHI, and PaCO2) were extracted by principal component analysis, and the cluster analysis revealed four clusters of various phenotypes with different clinical features. The subjects were middle-aged 
Table 2 Summary of the main features in the identified clusters

\begin{tabular}{|c|c|c|c|c|c|c|c|c|c|c|c|c|c|c|c|c|c|}
\hline & \multirow{2}{*}{\multicolumn{3}{|c|}{$\begin{array}{l}\text { All clusters } \\
N=1023\end{array}$}} & \multirow{2}{*}{\multicolumn{3}{|c|}{$\begin{array}{l}\text { Cluster } 1 \\
N=290\end{array}$}} & \multirow{2}{*}{\multicolumn{3}{|c|}{$\begin{array}{l}\text { Cluster } 2 \\
N=271\end{array}$}} & \multirow{2}{*}{\multicolumn{3}{|c|}{$\begin{array}{l}\text { Cluster } 3 \\
N=361\end{array}$}} & \multirow{2}{*}{\multicolumn{3}{|c|}{$\begin{array}{l}\text { Cluster } 4 \\
N=101\end{array}$}} & \multirow{3}{*}{$\begin{array}{l}p \text { value } \\
<0.0001\end{array}$} \\
\hline \multicolumn{2}{|c|}{ Patient characteristics } & & & & & & & & & & & & & & & & \\
\hline \multirow{3}{*}{$\begin{array}{l}\text { Age } \\
\text { Sex }\end{array}$} & \multirow{2}{*}{$\begin{array}{l}\text { Year } \\
(\mathrm{F} / \mathrm{M})\end{array}$} & \multirow{2}{*}{\multicolumn{2}{|c|}{$\begin{array}{l}51.41 \quad \pm \\
121 / 902\end{array}$}} & 13.34 & \multirow{2}{*}{$\begin{array}{l}51.82 \\
29 / 261\end{array}$} & \multirow{2}{*}{ \pm} & 12.71 & 49.10 & \pm & 12.93 & 55.24 & \pm & 13.29 & 42.71 & \multirow[t]{2}{*}{ \pm} & 10.96 & \\
\hline & & & & & & & & $29 / 242$ & & & $54 / 30$ & & & $9 / 92$ & & & \\
\hline & Female $\%$ & 11.8 & & & 10.0 & & & 10.7 & & & 15.0 & & & 8.9 & & & \\
\hline Smoker & $(n)$ & 249 & & & 58 & & & 67 & & & 86 & & & 38 & & & \\
\hline Ex-smoker & $(n)$ & 262 & & & 82 & & & 46 & & & 110 & & & 24 & & & \\
\hline BMI & $\left(\mathrm{kg} / \mathrm{m}^{2}\right)$ & 27.97 & \pm & 5.28 & 26.20 & \pm & 3.45 & 30.30 & \pm & 3.74 & 25.15 & \pm & 3.48 & 36.87 & \pm & 6.04 & $<0.0001$ \\
\hline Neck & $(\mathrm{cm})$ & 40.27 & \pm & 3.74 & 39.36 & \pm & 3.05 & 41.73 & \pm & 2.96 & 38.59 & \pm & 3.18 & 45.07 & \pm & 3.95 & $<0.0001$ \\
\hline Waist & $(\mathrm{cm})$ & 95.50 & \pm & 13.29 & 90.25 & \pm & 9.58 & 99.73 & \pm & 9.72 & 89.51 & \pm & 10.44 & 115.22 & \pm & 13.90 & $<0.0001$ \\
\hline Hip & $(\mathrm{cm})$ & 104.17 & \pm & 11.03 & 101.81 & \pm & 7.40 & 108.68 & \pm & 7.66 & 98.30 & \pm & 8.69 & 123.41 & \pm & 10.93 & $<0.0001$ \\
\hline ESS score & & 9.65 & \pm & 4.90 & 14.40 & \pm & 3.15 & 8.40 & \pm & 3.45 & 5.63 & \pm & 2.60 & 13.70 & \pm & 4.03 & $<0.0001$ \\
\hline
\end{tabular}

*ANOVA with Tukey with post hoc test, **Body Mass Index

ESS Epworth Sleepiness Scale

The cluster analysis identified four clusters. Compared with the Clusters 1 and 2, Cluster 3 was older and Cluster 4 youngest. There were no significant differences in the male-female ratio or history of smoking between the clusters. The BMI values, as well as the neck, waist, and hip circumferences, were the highest in Cluster 4. ESS scores were elevated in Clusters 1 and 4

patients around 50 years old, mostly male, tended to be obese, but did not tend to have high daytime sleepiness. As a result, severe OSA was more frequent.
Our research was inspired by previous studies, and we considered that phenotyping could influence the actual clinical practice. The anticipated result was that items that have

Table 3 Sleep characteristics

\begin{tabular}{|c|c|c|c|c|c|c|c|c|c|c|c|c|c|c|c|c|c|}
\hline \multirow[b]{3}{*}{ Awake } & \multirow[b]{3}{*}{$(\min )$} & \multirow{2}{*}{\multicolumn{3}{|c|}{$\begin{array}{l}\text { All clusters } \\
N=1023\end{array}$}} & \multirow{2}{*}{\multicolumn{3}{|c|}{$\begin{array}{l}\text { Cluster } 1 \\
N=290\end{array}$}} & \multirow{2}{*}{\multicolumn{3}{|c|}{$\begin{array}{l}\text { Cluster } 2 \\
N=271\end{array}$}} & \multirow{2}{*}{\multicolumn{3}{|c|}{$\begin{array}{l}\text { Cluster } 3 \\
N=361\end{array}$}} & \multirow{2}{*}{\multicolumn{3}{|c|}{$\begin{array}{l}\text { Cluster } 4 \\
N=101\end{array}$}} & \multirow{3}{*}{$\begin{array}{l}p \text { value } \\
0.0162\end{array}$} \\
\hline & & & & & & & & & & & & & & & & & \\
\hline & & 74.58 & \pm & 67.86 & 67.23 & \pm & 64.29 & 78.18 & \pm & 71.84 & 80.94 & \pm & 68.48 & 60.61 & \pm & 61.11 & \\
\hline REM & $(\min )$ & 65.57 & \pm & 34.23 & 72.12 & \pm & 34.82 & 57.68 & \pm & 33.04 & 67.64 & \pm & 33.85 & 58.69 & \pm & 32.25 & $<0.0001$ \\
\hline Awake & $(\%)$ & 14.64 & \pm & 13.53 & 12.91 & \pm & 12.36 & 16.01 & \pm & 15.22 & 15.67 & \pm & 13.37 & 11.78 & \pm & 11.69 & 0.0117 \\
\hline REM & $(\%)$ & 12.80 & \pm & 8.54 & 14.37 & \pm & 12.34 & 11.41 & \pm & 6.30 & 12.94 & \pm & 6.37 & 11.19 & \pm & 6.35 & 0.0004 \\
\hline SPT & & 502.03 & \pm & 54.74 & 509.73 & \pm & 48.77 & 490.57 & \pm & 59.12 & 502.02 & \pm & 58.57 & 510.21 & \pm & 34.64 & 0.0004 \\
\hline TST & & 439.84 & \pm & 88.90 & 452.57 & \pm & 82.99 & 426.28 & \pm & 96.24 & 436.12 & \pm & 88.60 & 453.65 & \pm & 80.48 & 0.0040 \\
\hline SE & & 0.87 & \pm & 0.14 & 0.89 & \pm & 0.13 & 0.86 & \pm & 0.14 & 0.87 & \pm & 0.14 & 0.89 & \pm & 0.14 & 0.1526 \\
\hline $\mathrm{CA}$ & $(\%)$ & 0.97 & \pm & 3.64 & 0.91 & \pm & 3.71 & 0.80 & \pm & 2.50 & 1.59 & \pm & 5.18 & 0.25 & \pm & 0.66 & 0.0118 \\
\hline $\mathrm{OA}$ & $(\%)$ & 24.17 & \pm & 19.21 & 17.20 & \pm & 15.52 & 32.27 & \pm & 18.94 & 15.21 & \pm & 13.52 & 37.82 & \pm & 21.39 & $<0.0001$ \\
\hline MA & $(\%)$ & 2.79 & \pm & 8.99 & 1.89 & \pm & 4.89 & 4.39 & \pm & 13.63 & 1.97 & \pm & 5.26 & 2.53 & \pm & 7.24 & 0.3506 \\
\hline $\mathrm{AI}$ & $(/ \mathrm{h})$ & 30.52 & \pm & 25.02 & 21.38 & \pm & 18.45 & 49.23 & \pm & 22.39 & 18.29 & \pm & 15.52 & 59.27 & \pm & 28.61 & $<0.0001$ \\
\hline $\mathrm{AHI}$ & $(/ \mathrm{h})$ & 47.43 & \pm & 24.98 & 36.17 & \pm & 18.66 & 69.63 & \pm & 15.19 & 31.74 & \pm & 15.37 & 76.30 & \pm & 21.55 & $<0.0001$ \\
\hline ODI3 & $(/ \mathrm{h})$ & 49.86 & \pm & 54.37 & 35.87 & \pm & 29.23 & 73.65 & \pm & 53.43 & 32.74 & \pm & 33.81 & 98.07 & \pm & 108.32 & $<0.0001$ \\
\hline Mean $\mathrm{SaO} 2$ & $(\%)$ & 93.37 & \pm & 3.95 & 94.63 & \pm & 2.51 & 91.78 & \pm & 3.55 & 95.04 & \pm & 1.97 & 88.01 & \pm & 6.52 & $<0.0001$ \\
\hline Arousal Index & $(/ \mathrm{h})$ & 42.03 & \pm & 23.02 & 34.16 & \pm & 17.02 & 56.00 & \pm & 20.02 & 31.34 & \pm & 15.53 & 68.20 & \pm & 29.63 & $<0.0001$ \\
\hline
\end{tabular}

*ANOVA with Tukey's post hoc test

$R E M$, rapid eye movement; $S P T$, sleep period time; $T S T$, total sleep time; $S E$, sleep effect; $C A$, central apnea; $O A$, obstructive apnea; $M A$, mixed apnea; $A I$, apnea index; $A H I$, Apnea-Hypopnea Index; $O D I$, oxygen desaturation index

Of the enrolled OSA patients, 95 (9\%) had mild (AHI 5-15/h), 200 (20\%) had moderate (AHI 15-30/h), and 728 (71\%) had severe (AHI > 30/h) OSA, with a mean AHI of $47 / \mathrm{h}$ and a mean oxygen desaturation index of 50/h. Sleep-disordered breathing data (obstructive apnea (OA), apnea index (AI), AHI, oxygen desaturation index 3\%, mean $\mathrm{SpO} 2$, and arousal index) was the worst in Cluster 4, followed by Cluster 2 
Table 4 Lung function tests and arterial blood gas analysis

\begin{tabular}{|c|c|c|c|c|c|}
\hline All clusters & Cluster 1 & Cluster 2 & Cluster 3 & Cluster 4 & $p$ value \\
\hline$N=1023$ & $N=290$ & $N=271$ & $N=361$ & $N=101$ & \\
\hline
\end{tabular}

\begin{tabular}{|c|c|c|c|c|c|c|c|c|c|c|c|c|c|c|c|c|c|}
\hline \multicolumn{18}{|c|}{ Lung function test } \\
\hline $\mathrm{VC}$ & (\% predicted) & 113.21 & \pm & 47.60 & 114.29 & \pm & 14.25 & 109.48 & \pm & 14.30 & 118.24 & \pm & 76.36 & 101.24 & \pm & 16.30 & 0.0094 \\
\hline FVC & (\% predicted) & 106.58 & \pm & 17.12 & 108.58 & \pm & 18.24 & 104.13 & \pm & 14.72 & 109.56 & \pm & 16.55 & 96.13 & \pm & 17.14 & $<0.0001$ \\
\hline $\mathrm{FEV}_{1.0}$ & (\% predicted) & 100.19 & \pm & 16.59 & 103.10 & \pm & 15.95 & 97.16 & \pm & 13.62 & 103.73 & \pm & 16.98 & 86.55 & \pm & 15.92 & $<0.0001$ \\
\hline $\mathrm{FEV}_{1.0} \%$ & $(\%)$ & 76.63 & \pm & 7.93 & 76.91 & \pm & 7.10 & 77.67 & \pm & 7.20 & 75.39 & \pm & 8.51 & 77.61 & \pm & 9.29 & 0.0035 \\
\hline MMF & ( $\%$ predicted) & 79.59 & \pm & 28.57 & 80.75 & \pm & 27.59 & 80.30 & \pm & 26.38 & 79.95 & \pm & 30.18 & 72.91 & \pm & 30.39 & 0.1249 \\
\hline V50 & (\% predicted) & 69.98 & \pm & 24.11 & 71.39 & \pm & 24.55 & 71.90 & \pm & 22.62 & 68.38 & \pm & 23.88 & 66.67 & \pm & 27.06 & 0.1214 \\
\hline V25 & ( $\%$ predicted) & 44.12 & \pm & 20.51 & 45.90 & \pm & 21.22 & 44.28 & \pm & 18.36 & 43.11 & \pm & 20.86 & 42.30 & \pm & 22.44 & 0.3016 \\
\hline \multicolumn{18}{|c|}{ Blood gas analysis } \\
\hline $\mathrm{pH}$ & & 7.40 & \pm & 0.03 & 7.40 & \pm & 0.02 & 7.40 & \pm & 0.04 & 7.41 & \pm & 0.03 & 7.39 & \pm & 0.02 & $<0.0001$ \\
\hline $\mathrm{PaCO} 2$ & $(\mathrm{mmHg})$ & 43.43 & \pm & 4.07 & 43.95 & \pm & 3.41 & 42.96 & \pm & 3.29 & 42.12 & \pm & 3.71 & 47.88 & \pm & 5.45 & $<0.0001$ \\
\hline $\mathrm{PaO} 2$ & $(\mathrm{mmHg})$ & 81.66 & \pm & 11.10 & 82.77 & \pm & 10.88 & 80.07 & \pm & 10.55 & 84.51 & \pm & 10.70 & 72.57 & \pm & 9.00 & $<0.0001$ \\
\hline $\mathrm{HCO} 3$ & $(\mathrm{mmoL} / \mathrm{L})$ & 26.59 & \pm & 1.92 & 26.72 & \pm & 1.71 & 26.38 & \pm & 1.71 & 26.21 & \pm & 1.88 & 28.23 & \pm & 2.23 & $<0.0001$ \\
\hline $\mathrm{SaO} 2$ & $(\%)$ & 96.17 & \pm & 1.57 & 96.38 & \pm & 1.45 & 95.86 & \pm & 1.63 & 96.57 & \pm & 1.34 & 94.86 & \pm & 1.71 & $<0.000$ \\
\hline
\end{tabular}

*ANOVA with Tukey's post hoc test

$V C$, vital capacity; $F V C$, forced vital capacity; $F E V$, forced expiratory volume; $M M F$, maximal mi-expiratory flow

Although no ventilatory dysfunction was observed, the forced vital capacity (FVC) and the forced expiratory volume $\left(\mathrm{FEV}_{1.0}\right)$ were the lowest in Cluster 4. There were no significant differences regarding the peripheral airway obstruction. Overall, $\mathrm{CO} 2$ tended to be high with metabolic compensation. Especially in Cluster 4, the mean value above $45 \mathrm{mmHg}$ was substantially increased. Besides, oxygen at rest tended to be low in this cluster

been previously linked to the severity of OSA, such as age [13], obesity [14], and daytime sleepiness [15], would be extracted as principal components. Previous reports made it clear that it is important to distinguish OSA types by phenotype [16]. However, these studies were not able to explain how phenotype and endotype are linked to this disease. We suggest that in all cases, the arterial blood gas analysis and leptin measurements are important tests to clarify the impact of OSA on respiratory control and lipid metabolism, i.e., the relationships between phenotypes and endotypes.

\section{Distinguishing factors of the identified subpopulations}

Interestingly, no significant differences between men and women were observed for each cluster. Cluster 4 had a significantly higher rate of smokers $(37 \%$ smokers; $61 \%$ if ex-smokers were included). Cluster 1 (middle age, symptomatic severe OSA) and Cluster 4 (young, obese, symptomatic very severe OSA) exhibited high leptin levels. C-reactive protein levels were also elevated in Cluster 4. In this group, the CRP and leptin levels were especially high indicating a different pathophysiological background, such as systemic inflammation or metabolic disorder, which we believe increases the cardiovascular risk [17]. Although not significantly different, Cluster 4 did exhibit a notably abnormal glucose tolerance. Counterregulatory hormones of insulin and the sympathetic nervous system impair the glucose utilization in brain tissue, reduce insulin secretion in pancreatic $\beta$ cells, and decrease insulin sensitivity in peripheral tissues, thereby leading to abnormal glucose metabolism [18].

\section{Shortcomings of ESS and AHI in defining these subgroups}

The correlation of the ESS score to indices of sleepdisordered breathing has been reported [12], but the classification into phenotypes generated groups with no correlation between the ESS score and severity of OSA. This suggests that sleepiness is affected by multiple elements, such as the duration of sleep, arousal response, and hypoxemia, which are not well reflected by this medical questionnaire.

Our data also show that severe OSA patients could not be described by AHI alone. This is because it is not possible to distinguish a disease state such as obesity hypoventilation syndrome (OHS). OHS is defined as hypoventilation $(\mathrm{PaCO} 2>45 \mathrm{mmHg})$ and obesity (BMI > 30), after the exclusion of other causes. The direct measurement of $\mathrm{CO} 2$ levels is often difficult; nevertheless, the assessment of ventilation abnormalities, as performed in the present study, is essential for the 
Table 5 Blood chemistry analysis

\begin{tabular}{|c|c|c|c|c|c|c|c|c|c|c|c|c|c|c|c|c|c|}
\hline \multirow[b]{3}{*}{ WBC } & \multirow[b]{3}{*}{$\left(\times 10^{3}\right)$} & \multirow{2}{*}{\multicolumn{3}{|c|}{$\begin{array}{l}\text { All clusters } \\
N=1023\end{array}$}} & \multirow{2}{*}{\multicolumn{3}{|c|}{$\begin{array}{l}\text { Cluster } 1 \\
N=290\end{array}$}} & \multirow{2}{*}{\multicolumn{3}{|c|}{$\begin{array}{l}\text { Cluster } 2 \\
N=271\end{array}$}} & \multirow{2}{*}{\multicolumn{3}{|c|}{$\begin{array}{l}\text { Cluster } 3 \\
N=361\end{array}$}} & \multirow{2}{*}{\multicolumn{3}{|c|}{$\begin{array}{l}\text { Cluster } 4 \\
N=101\end{array}$}} & \multirow{3}{*}{$\begin{array}{l}p \text { value } \\
<0.0001\end{array}$} \\
\hline & & & & & & & & & & & & & & & & & \\
\hline & & 6.89 & \pm & 1.92 & 6.46 & \pm & 1.86 & 7.42 & \pm & 1.92 & 6.40 & \pm & 1.56 & 8.44 & \pm & 2.08 & \\
\hline $\mathrm{RBC}$ & $\left(\times 10^{6}\right)$ & 4.76 & \pm & 0.49 & 4.73 & \pm & 0.47 & 4.80 & \pm & 0.46 & 4.66 & \pm & 0.49 & 5.11 & \pm & 0.50 & $<0.0001$ \\
\hline $\mathrm{Hb}$ & $(\mathrm{g} / \mathrm{dL})$ & 4.91 & \pm & 1.44 & 14.87 & \pm & 1.27 & 15.00 & \pm & 1.50 & 14.66 & \pm & 1.48 & 15.65 & \pm & 1.35 & $<0.0001$ \\
\hline Hct & $(\%)$ & 43.85 & \pm & 4.19 & 43.61 & \pm & 3.74 & 44.06 & \pm & 4.28 & 43.21 & \pm & 4.22 & 46.26 & \pm & 4.19 & $<0.0001$ \\
\hline Platelet & $\left(\times 10^{3} / \mu \mathrm{L}\right)$ & 250.09 & \pm & 60.15 & 245.45 & \pm & 55.68 & 251.72 & \pm & 58.47 & 251.25 & \pm & 63.92 & 254.46 & \pm & 62.55 & 0.4985 \\
\hline T-Bil & $(\mathrm{mg} / \mathrm{dL})$ & 0.63 & \pm & 0.27 & 0.63 & \pm & 0.27 & 0.61 & \pm & 0.26 & 0.64 & \pm & 0.27 & 0.60 & \pm & 0.27 & 0.3994 \\
\hline AST & $(\mathrm{U} / \mathrm{L})$ & 28.77 & \pm & 15.75 & 26.14 & \pm & 11.90 & 31.81 & \pm & 18.55 & 25.67 & \pm & 11.28 & 39.10 & \pm & 23.37 & $<0.0001$ \\
\hline ALT & $(\mathrm{U} / \mathrm{L})$ & 39.64 & \pm & 33.03 & 34.58 & \pm & 26.63 & 49.03 & \pm & 40.66 & 30.32 & \pm & & 62.34 & \pm & 43.37 & $<0.0001$ \\
\hline LDH & $(\mathrm{U} / \mathrm{L})$ & 188.57 & \pm & 60.96 & 182.33 & \pm & 35.42 & 197.95 & \pm & 96.21 & 180.44 & \pm & 41.07 & 210.24 & \pm & 49.89 & $<0.0001$ \\
\hline ALP & $(\mathrm{U} / \mathrm{L})$ & 235.83 & \pm & 68.98 & 224.55 & \pm & 60.98 & 243.17 & \pm & 71.25 & 235.07 & \pm & 70.69 & 250.51 & \pm & 73.50 & 0.0028 \\
\hline G-GTP & $(\mathrm{U} / \mathrm{L})$ & 64.91 & \pm & 59.36 & 55.27 & \pm & 41.81 & 74.57 & \pm & & 61.33 & \pm & & 79.35 & \pm & & $<0.0001$ \\
\hline T-Cho & $(\mathrm{mg} / \mathrm{dL})$ & 208.64 & \pm & 38.54 & 206.34 & \pm & 35.98 & 210.87 & \pm & & 205.94 & \pm & & 218.69 & \pm & 38.11 & 0.0194 \\
\hline HDL & $(\mathrm{mg} / \mathrm{dL})$ & 49.16 & \pm & 12.87 & 49.81 & \pm & 13.18 & 45.35 & \pm & 9.92 & 52.70 & \pm & 14.29 & 44.63 & \pm & & $<0.000$ \\
\hline LDL & $(\mathrm{mg} / \mathrm{dL})$ & 122.24 & \pm & 34.38 & 121.01 & \pm & 32.21 & 123.82 & \pm & 33.96 & 119.53 & \pm & 35.51 & 131.56 & \pm & & 0.0239 \\
\hline TG & $(\mathrm{mg} / \mathrm{dL})$ & 187.79 & \pm & 129.52 & 178.58 & \pm & 115.30 & 214.40 & \pm & 159.88 & 170.25 & \pm & 118.04 & 206.58 & \pm & 102.11 & 0.0002 \\
\hline FBS & $(\mathrm{mg} / \mathrm{dL})$ & 113.06 & \pm & 32.28 & 109.41 & \pm & 29.60 & 119.02 & \pm & 37.52 & 109.70 & \pm & 25.97 & 119.33 & \pm & 40.87 & 0.0014 \\
\hline $\mathrm{HbAlc}$ & $(\%)$ & 5.69 & \pm & 0.93 & 5.59 & \pm & 0.79 & 5.76 & \pm & 0.88 & 5.54 & \pm & 0.91 & 6.24 & \pm & 1.16 & 0.0014 \\
\hline BUN & $(\mathrm{mg} / \mathrm{dL})$ & 14.86 & \pm & 9.87 & 15.41 & \pm & 13.42 & 14.67 & \pm & 6.08 & 15.10 & \pm & 10.04 & 12.99 & \pm & 3.18 & 0.2174 \\
\hline Creatinine & (mg/dL) & 0.88 & \pm & 0.84 & 0.91 & \pm & 0.85 & 0.94 & \pm & 1.14 & 0.84 & \pm & 0.68 & 0.80 & \pm & 0.14 & 0.3503 \\
\hline UA & $(\mathrm{mg} / \mathrm{dL})$ & 6.20 & \pm & 1.46 & 6.07 & \pm & 1.45 & 6.57 & \pm & 1.36 & 5.87 & \pm & 1.41 & 6.83 & \pm & 1.54 & $<0.000$ \\
\hline BNP & $(\mathrm{pg} / \mathrm{mL})$ & 30.69 & \pm & 81.47 & 29.10 & \pm & 61.62 & 40.22 & \pm & 125.92 & 28.36 & \pm & 51.88 & 11.81 & \pm & 13.12 & 0.6852 \\
\hline $\operatorname{IgE}$ & (IU/mL) & 226.05 & \pm & 311.73 & 40.00 & \pm & 9.64 & 164.00 & \pm & 211.39 & 128.38 & \pm & 129.56 & 568.40 & \pm & 477.03 & 0.0705 \\
\hline h-CRP & (ng/mL) & 1616 & \pm & 3898 & 1472 & \pm & 3489 & 2029 & \pm & 1938 & 1121 & \pm & 1901 & 4786 & \pm & 12,132 & $<0.000$ \\
\hline
\end{tabular}

*ANOVA with Tukey's post hoc test

$W B C$, white blood cells; $R B C$, red blood cells; $H b$, hemoglobin; Hct, hematocrit; $T$-Bil, total bilirubin; AST, aspartate aminotransferase; $A L T$, alanine aminotransferase; $L D H$, lactate dehydrogenase; $A L P$, alkaline phosphatase; $G$ - $G T P$, gamma-glutamyl transferase; $T$-Cho, total cholesterol; $H D L-C$, high-density lipoprotein cholesterol; $L D L-C$, low-density lipoprotein cholesterol; $T G T G$, triglyceride; $F B S$, fasting blood sugar; $H b A l c$, hemoglobin A1c; $B U N$, blood urea nitrogen; $U A$, uric acid; $B N P$, brain natriuretic peptide; $\operatorname{Ig} E$, immunoglobulin $\mathrm{E}$; $h$ - $C R P$, high sensitive $\mathrm{C}$-reactive protein; $e G F R$, estimated glomerular filtration rate

The white and red blood cell count, as well as the hemoglobin levels, were increased in Clusters 2 and 4. Similarly, liver function parameters, uric acid levels, and the values of a high-sensitivity test that detect C-reactive protein (CRP) were increased, particularly in Cluster 4

determination of OSA severity. There are also differences in the metabolic dysfunction in each cluster so that it is difficult to determine the disease prognosis by AHI alone neither.

Table 6 Adipokines

\begin{tabular}{|c|c|c|c|c|c|c|c|c|c|c|c|c|c|c|c|c|c|}
\hline \multirow[b]{3}{*}{ Leptin } & \multirow[b]{3}{*}{$(\mathrm{ng} / \mathrm{mL})$} & \multirow{2}{*}{\multicolumn{3}{|c|}{$\begin{array}{l}\text { All clusters } \\
N=167\end{array}$}} & \multirow{2}{*}{\multicolumn{3}{|c|}{$\begin{array}{l}\text { Cluster } 1 \\
N=68\end{array}$}} & \multirow{2}{*}{\multicolumn{3}{|c|}{$\begin{array}{l}\text { Cluster } 2 \\
N=31\end{array}$}} & \multirow{2}{*}{\multicolumn{3}{|c|}{$\begin{array}{l}\text { Cluster } 3 \\
N=55\end{array}$}} & \multirow{2}{*}{\multicolumn{3}{|c|}{$\begin{array}{l}\text { Cluster } 4 \\
N=13\end{array}$}} & \multirow{3}{*}{$\begin{array}{l}p \text { value } \\
<0.0001\end{array}$} \\
\hline & & & & & & & & & & & & & & & & & \\
\hline & & 8.45 & \pm & 6.91 & 7.11 & \pm & 5.47 & 12.15 & \pm & 6.69 & 5.77 & \pm & 4.98 & 18.01 & \pm & 9.65 & \\
\hline Adiponectin & $(\mu \mathrm{g} / \mathrm{mL})$ & 4.24 & \pm & 4.57 & 3.73 & \pm & 2.57 & 4.72 & \pm & 6.11 & 4.96 & \pm & 5.76 & 2.77 & \pm & 1.58 & 0.2746 \\
\hline Leptin/adiponectin & 3.55 & \pm & 4.87 & 2.95 & \pm & 3.94 & 4.54 & \pm & 3.29 & 2.08 & \pm & 2.87 & 10.59 & \pm & 10.44 & 0.0013 & \\
\hline
\end{tabular}

*ANOVA with Tukey's post hoc test

Serum leptin and adiponectin levels were determined in 167 patients whose samples were still available and compared between the four clusters (Table 6). Of the identified clusters, Clusters 1 and 4 exhibited high leptin levels. Adiponectin/leptin ratios and adiponectin levels showed no clear differences between clusters 


\section{Subgroup-specific links to adipokines}

Obesity is a major factor for developing OSA; therefore, adipokine is critical in OSA pathophysiology. Most importantly, adipokine-leptin is closely related not only to obesity but also to the ventilation response. As a result, OSA patients have an increased leptin resistance as noted in past reports [19]. Leptin, however, was not a sufficient biomarker. This study classified the patients into characteristics and compared the leptin levels. We believe that leptin may be useful as a biomarker for OSA if such phenotyping is used.

\section{Consequences for clinical practice}

To improve patient's outcome, physicians would want to identify patients who would respond best to continuous positive airway pressure (CPAP) therapy and the patients that are at most risk for cardiovascular disease. In our study, we hypothesized that the effects of CPAP were high in groups that had metabolic dysfunction or central nervous system resistance to leptin's ventilation promoting effect. We also hypothesized that these groups could have reduced cardiovascular risk [20-22].

In this context, the extent to which CPAP therapy ensures a sufficient sleep duration should be taken into consideration. A short sleep duration results in lower leptin and elevated ghrelin levels, increasing the appetite and, thus, causing a vicious cycle with the progressing obesity [23].

A limitation of this study is that it is a retrospective study and that the sample size is small. Also, we did not consider the daily sleep duration or complications such as hypertension, cardiovascular disease, and diabetes. Prospective studies regarding the effects of CPAP therapy are needed.

\section{Conclusion}

The existence of multiple clinical phenotypes suggests that different pathophysiological backgrounds exist, such as systemic inflammation and metabolic disorder. This classification may be used to predict the efficacy of continuous positive airway pressure treatment that cannot be determined by the AHI.

Acknowledgments We wish to thank Tsuboi Eriko, Ikuko Takeshita, and Ohi Mina for their advice regarding the experimental design.

Code availability Not applicable

Data availability All data generated or analyzed during this study are included in this published article.

\section{Compliance with ethical standards}

Conflict of interest The authors declare that they have no conflict of interest.

Ethics approval Our study was approved by the Clinical Research Ethics Committee of the Nihon University Hospital (Protocol number RK-170509-07). Written informed consent was waived by the ethics committee. All protocols and practices have been conducted following the World Medical Association's Declaration of Helsinki.

Consent to participate Written informed consent was waived by the ethics committee.

\section{Consent for publication Not applicable}

Open Access This article is licensed under a Creative Commons Attribution 4.0 International License, which permits use, sharing, adaptation, distribution and reproduction in any medium or format, as long as you give appropriate credit to the original author(s) and the source, provide a link to the Creative Commons licence, and indicate if changes were made. The images or other third party material in this article are included in the article's Creative Commons licence, unless indicated otherwise in a credit line to the material. If material is not included in the article's Creative Commons licence and your intended use is not permitted by statutory regulation or exceeds the permitted use, you will need to obtain permission directly from the copyright holder. To view a copy of this licence, visit http://creativecommons.org/licenses/by/4.0/.

\section{References}

1. Ulfberg J, Carter N, Talbäck M, Edling C (1996) Excessive daytime sleepiness at work and subjective work performance in the general population and among heavy snorers and patients with obstructive sleep apnea. Chest 110:659-663

2. Nakayama-Ashida Y, Takegami M, Chin K, Sumi K, Nakamura T, Takahashi KI, Wakamura T, Horita S, Oka Y, Minami I, Fukuhara S, Kadotani H (2008) Sleep-disordered breathing in the usual lifestyle setting as detected with home monitoring in a population of working men in Japan. Sleep 31:419-425

3. Chobanian AV, Bakris GL, Black HR, Cushman WC, Green LA, Izzo JL Jr, Jones DW, Materson BJ, Oparil S, Wright JT Jr, Roccella EJ, National Heart, Lung, and Blood Institute Joint National Committee on Prevention, Detection, Evaluation, and Treatment of High Blood Pressure, National High Blood Pressure Education Program Coordinating Committee (2003) The Seventh Report of the Joint National Committee on Prevention, Detection, Evaluation, and Treatment of High Blood Pressure: the JNC 7 report. JAMA 289:2560-2572

4. Sateia MJ (2014) International classification of sleep disorders-third edition: highlights and modifications. Chest 146:1387-1394

5. Quan S, Gillin J, Littner M, Shepard J (1999) Sleep-related breathing disorders in adults: recommendations for syndrome definition and measurement techniques in clinical research. The Report of an American Academy of Sleep Medicine Task Force. Sleep 22:667-689

6. Berger S, Polotsky VY (2018) Leptin and leptin resistance in the pathogenesis of obstructive sleep apnea: a possible link to oxidative stress and cardiovascular complications. Oxid Med Cell Longev 2018:5137947

7. Pan WW, Myers MG Jr (2018) Leptin and the maintenance of elevated body weight. Nat Rev Neurosci 19:95-105 
8. Makinodan K, Yoshikawa M, Fukuoka A, Tamaki S, Koyama N, Yamauchi M, Tomoda K, Hamada K, Kimura H (2008) Effect of serum leptin levels on hypercapnic ventilatory response in obstructive sleep apnea. Respiration 75:257-264

9. O'Neil SE, Lundbäck B, Lötvall J (2011) Proteomics in asthma and COPD phenotypes and endotypes for biomarker discovery and improved understanding of disease entities. J Proteomics 75:192-201

10. Ye L, Pien GW, Ratcliffe SJ, Björnsdottir E, Arnardottir ES, Pack AI, Benediktsdottir B, Gislason T (2014) The different clinical faces of obstructive sleep apnoea: a cluster analysis. Eur Respir J 44:1600-1607

11. (1995) Standardization of spirometry, 1994 Update. American Thoracic Society. Am J Respir Crit Care Med 152:1107-1136. https://doi.org/10.1164/ajrccm.152.3.7663792

12. Johns MW (1991) A new method for measuring daytime sleepiness: the Epworth sleepiness scale. Sleep 14:540-545

13. Edwards BA, O'Driscoll DM, Ali A, Jordan AS, Trinder J, Malhotra A (2010) Aging and sleep: physiology and pathophysiology. Semin Respir Crit Care Med 31:618-633

14. Patil SP, Schneider H, Schwartz AR, Smith PL (2007) Adult obstructive sleep apnea: pathophysiology and diagnosis. Chest 132: 325-337

15. Chiu HY, Chen PY, Chuang LP, Chen NH, Tu YK, Hsieh YJ, Wang YC, Guilleminault C (2017) Diagnostic accuracy of the Berlin questionnaire, STOP-BANG, STOP, and Epworth sleepiness scale in detecting obstructive sleep apnea: a bivariate metaanalysis. Sleep Med Rev 36:57-70
16. Ramos AR, Figueredo P, Shafazand S, Chediak AD, Abreu AR, Dib SI, Torre C, Wallace DM (2017) Obstructive sleep apnea phenotypes and markers of vascular disease: a review. Front Neurol 8:659

17. Li Y, Zhong X, Cheng G, Zhao C, Zhang L, Hong Y, Wan Q, He R, Wang Z (2017) Hs-CRP and all-cause, cardiovascular, and cancer mortality risk: a meta-analysis. Atherosclerosis 259:75-82

18. Spiegel K, Leproult R, Van Cauter E (1999) Impact of sleep debt on metabolic and endocrine function. Lancet 354:1435-1439

19. Reichmuth KJ, Austin D, Skatrud JB, Young T (2005) Association of sleep apnea and type II diabetes: a population-based study. Am J Respir Crit Care Med 172:1590-1595

20. Stelmach-Mardas M, Mardas M, Iqbal K, Kostrzewska M, Piorunek T (2017) Dietary and cardio-metabolic risk factors in patients with Obstructive Sleep Apnea: cross-sectional study. PeerJ 5:e3259

21. Shechter A (2017) Obstructive sleep apnea and energy balance regulation: a systematic review. Sleep Med Rev 34:59-69

22. Tachikawa R, Ikeda K, Minami T, Matsumoto T, Hamada S, Murase K, Tanizawa K, Inouchi M, Oga T, Akamizu T, Mishima M, Chin K (2016) Changes in energy metabolism after continuous positive airway pressure for obstructive sleep apnea. Am J Respir Crit Care Med 194:729-738

23. Taheri S, Lin L, Austin D, Young T, Mignot E (2004) Short sleep duration is associated with reduced leptin, elevated ghrelin, and increased body mass index. PLoS Med 1:e62

Publisher's note Springer Nature remains neutral with regard to jurisdictional claims in published maps and institutional affiliations. 